\title{
MATHEMATICAL MODEL'S CHOICE REASONING AND ITS IMPLEMENTATION FOR THE EVALUATION OF THE STRENGTH OF TECHNOLOGICAL VESSELS
}

\author{
Andrii Karpash \\ Zond, Research and Production Firm \\ Str. Mykytynetska 5a, Ivano-Frankivsk, Ukraine, 76000 \\ ankarpash@gmail.com \\ Andrii Oliinyk \\ Department of Mathematical Methods of Engineering \\ Ivano-Frankivsk National Technical University of Oil and Gas \\ Str. Karpatska 15, Ivano-Frankivsk, Ukraine, 76000 \\ andrij-olijnyk@rambler.ru
}

\begin{abstract}
In connection with the global increase in the intensity of use of working equipment related to high-risk facilities and the expiry of the service life limit, the question arises of determining the actual technical condition and forecasting the residual resource. From the analysis of the approaches to determining the technical state and on the analysis of regulatory documents, it becomes clear that the regulated methods of assessing the technical state are obsolete, such that they do not ensure the reliability of the obtained control results.

A new technique for determining the actual technical state through monitoring the level of stresses in the body of high-risk objects is proposed. The new technique takes into account additional physical and mechanical parameters that affect the stress-strain state, and have not yet been used. In other words, the technique of multivariable control of stress determination was proposed.

Mathematical models of the process of deformation and stress for cylindrical vessels with a spherical and conic dome operating under the action of high pressure are proposed.
\end{abstract}

Keywords: high pressure vessels, mathematical model of stress state of vessels, method of associative analysis.

\section{Introduction}

The objects of increased danger are operated practically in each sector of industry, which are different in their structure and principle of operation. This is a wide range of mechanisms and process equipment, which, as a rule, operate under various operating conditions and under conditions of long-term operation.

Determination of the actual technical condition and the service life limit is an interesting and actual direction for operating organizations. This list is evidenced by many reasons:

- intensification of production processes is increasing at enterprises;

- the level of operational loads is increasing;

- there are new requirements for technological equipment;

- the remaining resource is spent or is on the verge of its end;

- the level of rearmament and reconstruction of equipment is quite low.

Having enough information about the technical condition of the facility, the operator can characterize and establish safe operation parameters at a specific time of operation. Greater informativity will allow to predict the behavior of the technical state of the working object in the process of changing operating parameters. The condition for predicting the technical condition is the uninterrupted and reliable operation of the facility.

The main objective and mandatory requirement for the operator is the reliability of the results obtained to determine the actual technical condition of the process equipment. Therefore, new methods and approaches in this direction are necessary and relevant.

To ensure the conditions given above, a new technique for determining the actual technical state through monitoring the stress level in the metal of high-risk objects is proposed. The new 
technique represents mathematical models of the deformation and stress state of vessels operating under pressure, taking into account additional physical and mechanical parameters.

\section{Literature review and problem statement}

From the analysis of known methods of controlling the physical and mechanical properties of the material [1-5] and from the practice of specialized organizations that conduct technical diagnosis of long-term operation objects, it follows that the evaluation of the actual technical condition is carried out by one or two informative parameters. In most cases, this is the thickness of the wall and the hardness of the metal, which is not enough to fully characterize the state of the object. Based on the results of other control methods, existing defects are identified that require elimination, that is, a situation arises that results in stopping, operating and repairing equipment. The method of acoustic emission is described in [6]. The essence of the method consists in the analysis of acoustic signals, directly depend on the elastic and plastic deformation, as well as on the applied load.

The disadvantage of the method is the impossibility of monitoring without the applied load. Work [7] presents the results of research in the development of methods and technical means for monitoring the physical and mechanical characteristics of metal structures. In particular, the problems of determining the yield strength, ultimate strength and toughness for a complex of informative parameters (magnetic parameters, hardness, thermal conductivity, etc.) are considered. In [8], the disadvantages of the methods of monitoring the technical state by separate parameters are presented. Advantages of using multivariable control are given. An overview of three magnetic methods for nondestructive testing, in particular magnetic flux, Barkhausen noise and magnetic memory of metal, is presented in [9]. The first two are active methods, and the last is passive. The physical mechanisms of the methods and experimental studies are analyzed. In work [10], an evaluation of the method for determining the stress in a sample of steel subjected to a static load (tensile test) is described. Measurements of deformation are presented using traditional extensometers and optical systems. 3D model of material deformation and displacement fields in the axial and radial directions is also calculated.

Analysis of methods for controlling the physical and mechanical properties of metals shows the absence of a comprehensive approach to determining the stress state of metal structures. Known approaches to determine the actual technical state do not take into account a set of informative parameters that represent individual factors of influence.

It should be noted that one of the main parameters of the technical state is its stress-strain state (SSS), which occurs even at the stage of manufacturing and installation of the facility and is constantly changing in the process of operating technological equipment $[11,12]$. In other words, SSS depends on a certain number of factors that affect the exploited facility. If a number of necessary factors of influence to identify and develop an approach to measuring the informative parameters that these factors will represent, we will obtain a methodology for multivariable control. And this will allow obtaining a multifaceted characteristic of the stressed state of the exploited object. Understanding the behavior and the cause of the change in the stress state and premature correction of operating conditions, help prevent the occurrence of stress concentrators and subsequent formations of defects and failures.

The main disadvantage of the methods of SSS control at operation sites is the complexity of its conduct in the field and expensive equipment.

From the analysis of the normative and technical base [13-16], which regulates the definition and monitoring of the actual technical condition, some of the factors of influence shown in Fig. 1 are not taken into account, resulting in distortion of actual data directly obtained during the process of the control itself.

From the practice of monitoring the technical condition of equipment, there are many cases when operating organizations, in addition to standard, regulated programs, require additional methods for diagnosing technological equipment. The task of the additional survey is obtaining information and analyzes the physical and mechanical characteristics of the metal, taking into account the factors of influence that are not taken into account in the regulated program. 
The expected result is an increase in the accuracy of determining the actual technical condition and predicting the residual life of the equipment.

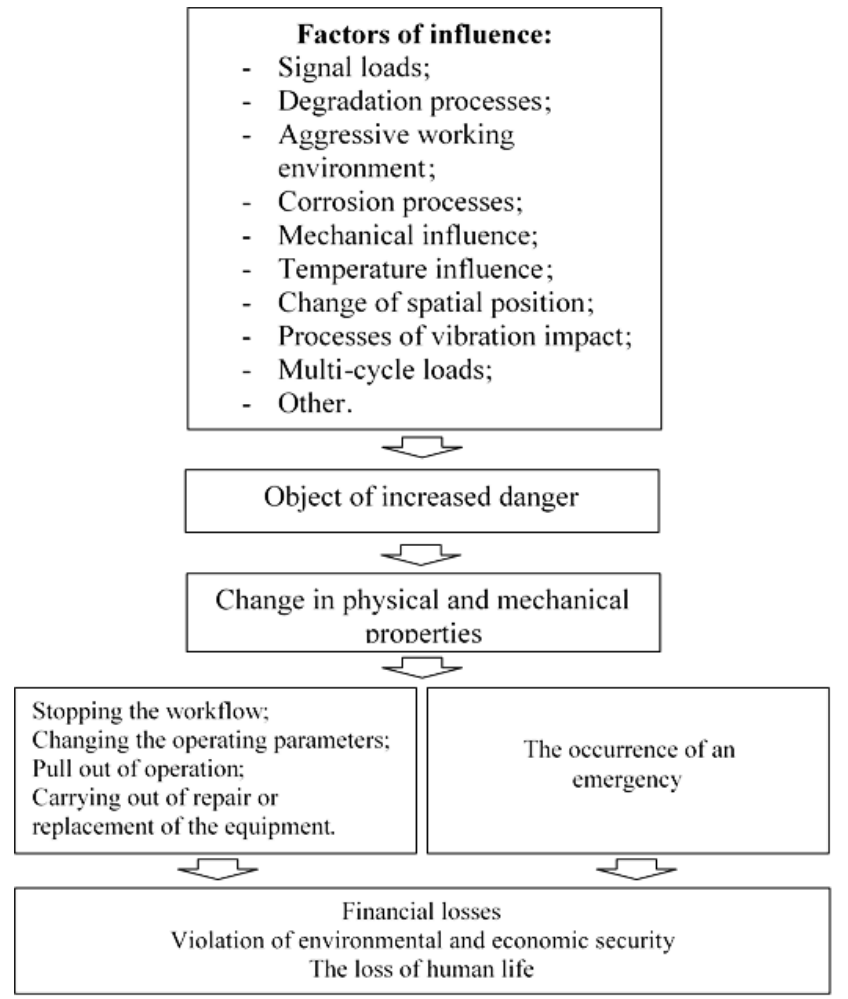

Fig. 1. Factors affecting the operation object

Therefore, in order to obtain the most accurate information when determining and monitoring the SSS of long-term operation facilities, it is effective:

- the use of multivariable control (the advantage is a comprehensive assessment, taking into account many factors and factors affecting the behavior of the change in the stress state);

- construction and implementation of mathematical models of SSS on the obtained control parameters.

\section{The aim and objectives of research}

The aim of research is development of a new approach to monitoring and assessing the actual technical condition of high-risk facilities that will simplify and reduce the cost of monitoring the actual technical condition, save time and human resources, obtain reliable data on the state of the facility through the use of a set of informative parameters that characterize the real factors of impact on the object.

To achieve this aim, the following tasks are set:

1. Set the type of the mathematical model for determining the parameters of the stress state after changing the spatial configuration of the object.

2. Develop a new technique for determining stresses, taking into account a set of informative parameters that depend on the change in force factors.

3. Develop a methodology for identifying factors on which an asymmetric change in the stress-strain state depends on the method of associative analysis.

\section{Materials and methods for research of the stress-strain state of vessels operating under pressure and factors of force action}

The efficiency of the operation of vessels operating under the influence of high pressure depends on current information about the parameters of the technical condition, and in particular 
SSS [11]. In the process of functioning of systems, they are exposed to a complex of force factors. The material of these objects are deteriorated, its physical and mechanical characteristics change. This can lead to the appearance of gradual and sudden failures due to material defects and, as a consequence, to the disruption of the construction continuity. An important factor in the force impact is also a violation of the symmetry of the structure due to subsidence of the ground, landslides, earthquakes, the intensity of vibration effects, temperature gradients, and the like. Considering industrial systems as modeling objects (Fig. 2), it is possible to offer a formal approach to the description of functioning. The input and output characteristics of the systems determining the deformation of the object of investigation are determined:

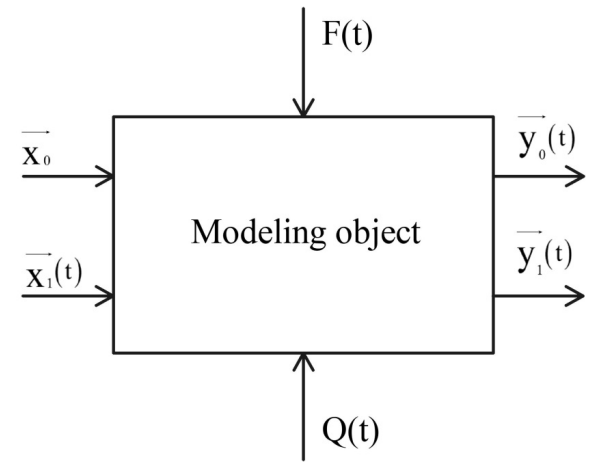

Fig. 2. The main characteristics of high pressure vessels as a simulation object

In the operation process of the modeling object (MO), which is characterized by some initial characteristics $\overrightarrow{\mathrm{x}_{0}}$, which are of a permanent nature (geometric dimensions, general constructive scheme), and $\overrightarrow{\mathrm{x}_{1}}(\mathrm{t})$, which are time variables (operating conditions, seasonal weather factors, force factors, material properties), actions of perturbing factors on MO occur. The disturbing factors are non-stationary in nature and can either permanently act on $\mathrm{MO} \mathrm{Q}(\mathrm{t})$ (own weight, the reaction forces of soils and foundations, the consequences of possible defects committed during the MO construction), or have a temporary character $\mathrm{F}(\mathrm{t})$ (the action of non-design power factors, aerodynamic loads, changes in physical-mechanical, electrical characteristics due to long-term operation of objects).

In the process of $\mathrm{MO}$ operation, the initial characteristics change, which leads to the fact that the real MO position is characterized by new values $\overrightarrow{\mathrm{y}_{0}}$ and $\overrightarrow{\mathrm{y}_{1}}(\mathrm{t})$, which differ from the original characteristics $\overrightarrow{\mathrm{x}_{0}}$ and $\overrightarrow{\mathrm{x}_{1}}(\mathrm{t})$.

The main parameters that characterize the ability of these industrial objects to perform the tasks are strength, stability and stress, as well as the possibility of permissible displacement of structures that does not lead to violations of stable functioning. All these characteristics can be combined into a single indicator that can be considered a priority for assessing the technical condition and residual life of MO: vessels that are under the influence of high pressure and SSS.

Such generalization is quite motivated, since practically all factors of negative influence, which cause the appearance of defects and failures of MO, act on the SSS parameters, on the emergence of critical stress values in the material. Thus, the general functional equation describing the modeling object (vessel, operated under the action of high pressure) can be written in the following form:

$$
\left\{\begin{array}{c}
\overrightarrow{y_{0}} \\
\overrightarrow{y_{1}}(t)
\end{array}\right\}=A\left(Q(t), F(t), \overrightarrow{x_{0}}, \overrightarrow{x_{1}}(t)\right)\left\{\begin{array}{c}
\overrightarrow{x_{0}} \\
\overrightarrow{x_{1}}(t)
\end{array}\right\},
$$

where $\mathrm{A}\left(\mathrm{Q}(\mathrm{t}), \mathrm{F}(\mathrm{t}), \overrightarrow{\mathrm{x}_{0}}, \overrightarrow{\mathrm{x}_{1}}(\mathrm{t})\right)$ - some operator that takes into account the effect on the object of the initial and perturbing factors described above. Depending on (1), the unknowns are the quantities $\overrightarrow{\mathrm{y}_{0}}, \overrightarrow{\mathrm{y}_{1}}(\mathrm{t})$, although in many cases the information about $\mathrm{Q}(\mathrm{t})$ and $\mathrm{F}(\mathrm{t})$, their quantitative characteristics, the topology of the action, etc. are not enough or completely absent. 
In this case, problem (1) can be put in the form of a functional equation of the form:

$$
\left\{\begin{array}{c}
\overrightarrow{y_{0}} \\
\overrightarrow{y_{1}}(t)
\end{array}\right\}=A\left(\overrightarrow{x_{0}}, \overrightarrow{x_{1}}(t)\right)\left\{\begin{array}{c}
\overrightarrow{x_{0}} \\
\overrightarrow{x_{1}}(t)
\end{array}\right\}
$$

In addition, in many cases equation (2) can be written in the following form:

$$
\left\{\begin{array}{c}
\overrightarrow{y_{0}} \\
\overrightarrow{y_{1}}(t)
\end{array}\right\}=A_{H}\left\{\begin{array}{c}
\overrightarrow{x_{0}} \\
\overrightarrow{x_{1}}(t)
\end{array}\right\},
$$

where $\mathrm{A}_{\mathrm{H}}$ - some operator, usually with an unknown structure that takes the $\mathrm{MO}$ of state $\left(\overrightarrow{\mathrm{x}_{0}}, \overrightarrow{\mathrm{x}_{1}}(\mathrm{t})\right)$ to the state $\left(\overrightarrow{\mathrm{y}_{0}}, \overrightarrow{\mathrm{y}_{1}}(\mathrm{t})\right)$ and plays the role of a kind of "black box" when only the initial and final state of the system is known. The situation (3) is the most characteristic for the modeling of objects, which, on the one hand, are under the influence of known, but those that are difficult formalized force factors, and on the other hand, the parameters $\left(\overrightarrow{\mathrm{x}_{0}}, \overrightarrow{\mathrm{x}_{1}}(\mathrm{t})\right)$ and $\left(\overrightarrow{\mathrm{y}_{0}}, \overrightarrow{\mathrm{y}_{1}}(\mathrm{t})\right)$. As a rule, problems (2), (3) belong to the class of ill-posed regularization problems (transformation into the correct problem) for which it is necessary to develop special algorithms. As for problem (1), it is, as a rule, well posed and the complexity of the solution is determined only by the structure of the operator $\mathrm{A}\left(\mathrm{Q}(\mathrm{t}), \mathrm{F}(\mathrm{t}), \overrightarrow{\mathrm{x}_{0}}, \overrightarrow{\mathrm{x}_{1}}(\mathrm{t})\right)$.

The problem of evaluation of the change in the stress-strain state of vessels under high pressure is referred to and solved in the form (3). The problem of reconstructing the nature and structure $\mathrm{A}_{\mathrm{H}}$ is solved on the basis of experimentally known sets of parameters $\left(\overrightarrow{\mathrm{x}_{0}}, \overrightarrow{\mathrm{x}_{1}}(\mathrm{t})\right)$ and $\left(\overrightarrow{\mathrm{y}_{0}}, \overrightarrow{\mathrm{y}_{1}}(\mathrm{t})\right)$.

When studying the stress state of vessels working under pressure, the approach modeled and justified in [11] is used. According to this approach, the technique for determining the component of the stress tensor and deformations using known coordinates of a certain set of points on the surface of the object is used to evaluate the change in the SSS. For this object, a parametric representation of it as a three-dimensional deformed body is known at the initial and control time. In this case, the components of the stress tensor and strains are calculated without using, as a rule, unknown information about the forces and load, which cause such change in the spatial configuration. Two types of pressure vessels are considered: with spherical and conical upper parts. Vessel with a spherical dome is shown in Fig. 3. The following parametric representation in the spherical and cylindrical (for the upper part) coordinate systems is valid in the initial (not deformed) moment of time for the coordinates of the points of the vessel surface:

$$
\begin{gathered}
\left\{\begin{array}{cc}
\mathrm{x}=\mathrm{r} \cos \varphi, & 0 \leq \varphi \leq \mathrm{r}_{\mathrm{n} p} ; \\
\mathrm{y}=\mathrm{r} \sin \varphi, & \mathrm{R}_{\mathrm{ID}} \leq \mathrm{r} \leq \mathrm{R}_{\mathrm{OD}} ; \\
\mathrm{z}=\mathrm{S}, & 0 \leq \mathrm{S} \leq \mathrm{L} ;
\end{array}\right. \\
\left\{\begin{array}{cc}
\mathrm{r} & \begin{array}{c}
\pi \\
\mathrm{x}=\mathrm{r} \sin \theta \cos \varphi,
\end{array} \\
\mathrm{y}=\mathrm{r} \sin \theta \sin \varphi, & \mathrm{R}_{\mathrm{OD}}^{\prime} \leq \mathrm{r} \leq \mathrm{R}_{\mathrm{ID}}^{\prime} ; \\
\mathrm{z}=\mathrm{r} \cos \theta, & 0 \leq \varphi \leq 2 \pi .
\end{array}\right.
\end{gathered}
$$

It should be noted that before the end of the cylindrical part of the representation is carried out in a cylindrical coordinate system, and for a spherical part in a spherical part, the angle $\theta_{0}$ specifies the angle of conjugation of these two parts (Fig. 3). The coordinates $r$ for these two parts will satisfy the conjugation conditions $\mathrm{R}_{\mathrm{ID}}=\mathrm{R}_{\mathrm{ID}} \cos \theta$ and $\mathrm{R}_{\mathrm{OD}}=\mathrm{R}_{\mathrm{OD}} \cos \theta$. 


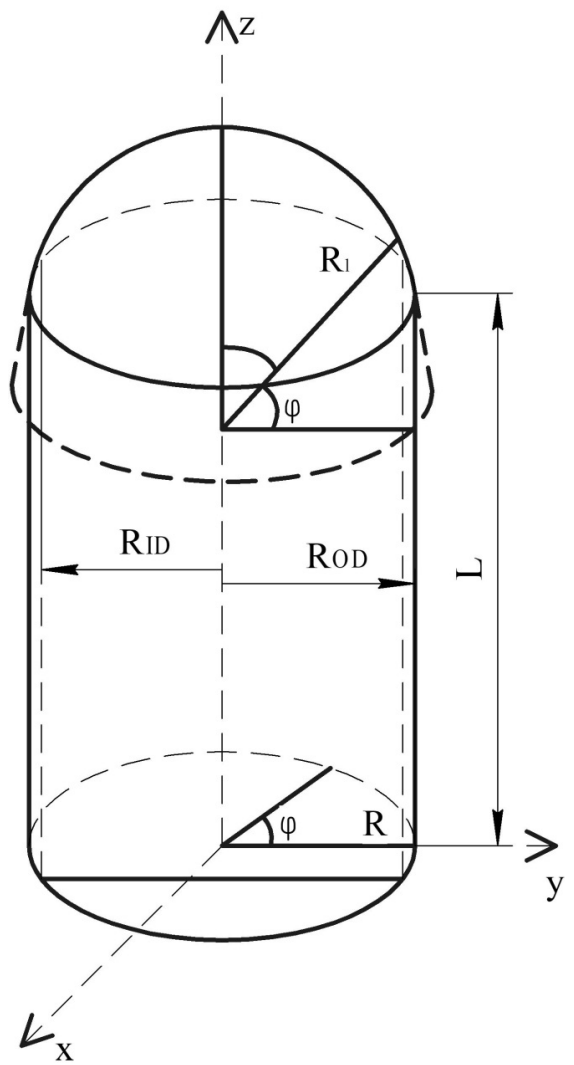

Fig. 3. Vessel with spherical configuration of the upper part

At the control point in time, the representation (4) acquires a different kind.

$$
\left\{\begin{array}{l}
x=X_{L}-R n_{x}+\rho(S, \varphi, r, t) \cos \omega(S, \varphi, r, t) b_{x}+\rho(S, \varphi, r, t) \sin \omega(S, \varphi, r, t) n_{x}+\psi(S, \varphi, r, t) \tau_{x} \\
y=Y_{L}-R n_{y}+\rho(S, \varphi, r, t) \cos \omega(S, \varphi, r, t) b_{y}+\rho(S, \varphi, r, t) \sin \omega(S, \varphi, r, t) n_{y}+\psi(S, \varphi, r, t) \tau_{y} \\
z=Z_{L}-R n_{z}+\rho(S, \varphi, r, t) \cos \omega(S, \varphi, r, t) b_{z}+\rho(S, \varphi, r, t) \sin \omega(S, \varphi, r, t) n_{z}+\psi(S, \varphi, r, t) \tau_{z}
\end{array}\right.
$$

where $\rho(\mathrm{S}, \varphi, \mathrm{r}, \mathrm{t}) ; \omega(\mathrm{S}, \varphi, \mathrm{r}, \mathrm{t}) ; \Psi(\mathrm{S}, \varphi, \mathrm{r}, \mathrm{t})$ - the functions that find the displacements of points in the radial, tangential and longitudinal directions; $\vec{r}_{L}\left(X_{L} Y_{L} Z_{L}\right)$ - coordinates of points on the axis of the pipe; $\vec{n}\left(n_{x} n_{y} n_{z}\right) ; \vec{b}\left(b_{x} b_{y} b_{z}\right) ; \vec{\tau}\left(\tau_{x} \tau_{y} \tau_{z}\right)$ - the components of the normal vectors, the binormal and the tangent to the tube axis. conditions:

In practical calculations, the functions $\rho(\mathrm{S}, \varphi, \mathrm{r}, \mathrm{t}) ; \omega(\mathrm{S}, \varphi, \mathrm{r}, \mathrm{t}) ; \Psi(\mathrm{S}, \varphi, \mathrm{r}, \mathrm{t})$ satisfy the following

$$
\begin{gathered}
\rho(\mathrm{S}, \varphi, r, \mathrm{t}) \approx \mathrm{r}+\mathrm{r}_{1}(\mathrm{~S}, \varphi, \mathrm{r}, \mathrm{t}), \\
\omega(\mathrm{S}, \varphi, \mathrm{r}, \mathrm{t}) \approx \varphi+\varphi_{1}(\mathrm{~S}, \varphi, \mathrm{r}, \mathrm{t}), \\
\psi(\mathrm{S}, \varphi, \mathrm{r}, \mathrm{t}) \approx \psi+\psi_{1}(\mathrm{~S}, \varphi, r, \mathrm{t}),
\end{gathered}
$$

where $\left|\mathrm{r}_{1}(\mathrm{~S}, \varphi, \mathrm{r}, \mathrm{t})\right| \ll 1 ;\left|\varphi_{1}(\mathrm{~S}, \varphi, \mathrm{r}, \mathrm{t})\right| \ll 1 ;\left|\psi_{1}(\mathrm{~S}, \varphi, \mathrm{r}, \mathrm{t})\right| \ll 1$ that is, the pipe generally retains a cylindrical configuration. To describe the spherical part, either the second representation is taken in (1) or the radii of curvature of the spherical part are listed from the results of experimental measurements of the coordinates of the upper part. Let's suppose that the coordinates of the points $\left(\mathrm{x}_{\mathrm{i}} \mathrm{y}_{\mathrm{i}} \mathrm{z}_{\mathrm{i}}\right)$ are organized on the upper part, then minimizing the function:

$$
\mathrm{S}\left(\mathrm{x}_{0} ; \mathrm{y}_{0} ; \mathrm{z}_{0} ; \mathrm{R}\right)=\sum_{\hat{\mathrm{o}}=1}^{\mathrm{N}}\left[\left(\mathrm{x}_{\mathrm{i}}-\mathrm{x}_{0}\right)^{2}+\left(\mathrm{y}_{\mathrm{i}}-\mathrm{y}_{0}\right)^{2}+\left(\mathrm{z}_{\mathrm{i}}-\mathrm{z}_{0}\right)^{2}-\mathrm{R}^{2}\right]^{2},
$$


find the new coordinates of the center of the spherical part $\left(\mathrm{x}_{0} ; \mathrm{y}_{0} ; \mathrm{z}_{0}\right)$ and the radius of the deformed sphere. Optimization (7) is carried out by finding the expression for $\mathrm{R}^{2}$ : differentiates (7) with respect to $\mathrm{R}$, resulting in:

$$
\mathrm{R}^{2}=\frac{1}{\mathrm{~N}} \sum\left[\left(\mathrm{x}_{\mathrm{i}}-\mathrm{x}_{0}\right)^{2}+\left(\mathrm{y}_{\mathrm{i}}-\mathrm{y}_{0}\right)^{2}-\left(\mathrm{z}_{\mathrm{i}}-\mathrm{z}_{0}\right)^{2}-\mathrm{R}^{2}\right]
$$

after which the given expression is substituted in (7) and we obtain the problem of finding the coordinates $\left(\mathrm{x}_{0}, \mathrm{y}_{0}, \mathrm{z}_{0}\right)$, which obviously has a unique solution, because with this substitution the problem of minimizing a positive definite quadratic form is obtained. This allows to uniquely calculate the center $\left(\mathrm{x}_{0}, \mathrm{y}_{0}, \mathrm{z}_{0}\right)$ and the radius $\mathrm{R}$ of the deformed dome of the vessel.

According to the data for the conical upper part, which is shown in Fig. 4, similarly to (4) for the second system describing the conical part, the following representation holds:

$$
\left\{\begin{array}{cc}
\mathrm{x}=\mathrm{r} \cos \varphi, & 0 \leq \varphi \leq \mathrm{r}_{\text {ñ }} ; \\
\mathrm{y}=\mathrm{r} \sin \varphi, & \mathrm{L} \leq \mathrm{S} \leq \mathrm{L}_{1} ; \\
\mathrm{z}=\mathrm{S}, & 0 \leq \mathrm{r}(\mathrm{S}) \leq \mathrm{R}_{\mathrm{OD}},
\end{array}\right.
$$

where $\mathrm{L}_{1}$ determines the angle at the base of the conic section:

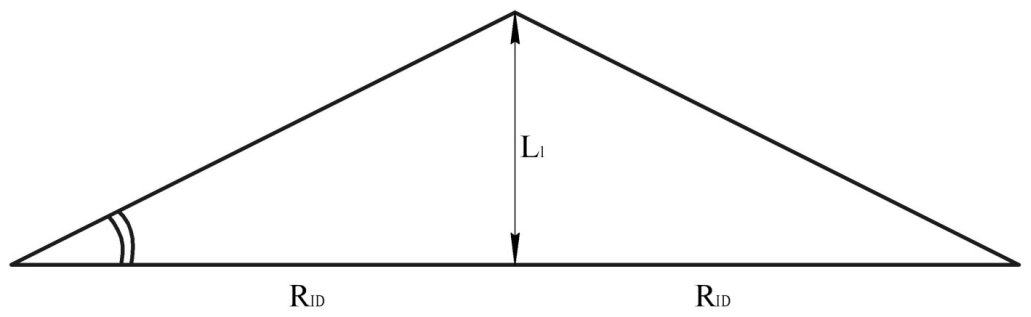

Fig. 4. Formalization of the conical part

At the control time, the coordinates of the cylindrical part are described with (5), the description of the conical part or remains the same as in (9), or can be refined from the results of measurements of a certain set of coordinates of the points of the conical part. If denote $\overrightarrow{\mathrm{R}_{0}}(\mathrm{~S}, \varphi, \mathrm{r}, \mathrm{t})$ ) radius vector of each point of the not deformed vessel under pressure, and $\vec{r}(S, \varphi, r, t)$ is the radius vector at the control moment, where the representations (4)-(9) allow to determine the following values:

- components of the vectors of local bases [17]:

$$
\begin{aligned}
& \overline{\mathrm{E}_{0}^{3}}=\frac{\overline{\mathrm{R}_{0}}}{\mathrm{x}_{\mathrm{i}}} \quad \mathrm{x}_{1}=\mathrm{S} ; \mathrm{x}_{2}=\varphi ; \mathrm{x}_{3}=\mathrm{r} ; \\
& \overline{\mathrm{E}^{3}}=\frac{\partial \overline{\mathrm{r}}}{\partial \mathrm{x}_{\mathrm{i}}} \quad \mathrm{x}_{1}=S ; \mathrm{x}_{2}=\varphi ; \mathrm{x}_{3}=r ;
\end{aligned}
$$

- components of the metric tensor at two points in time:

$$
\begin{gathered}
\mathrm{g}_{\mathrm{ij}}^{0}=\overline{\mathrm{E}_{0}^{\mathrm{i}}} \overline{\mathrm{E}_{0}^{\mathrm{j}}}, \quad \mathrm{j}, \mathrm{i}=1,2,3, \\
\mathrm{~g}_{\mathrm{ij}}=\overline{\mathrm{E}^{\mathrm{i}} \overline{\mathrm{E}^{\mathrm{j}}}} ;
\end{gathered}
$$

- components of the strain tensor:

$$
\stackrel{\circ}{i j}_{i j}=\frac{1}{2}\left(g_{i j}-g_{i j}^{0}\right) ;
$$


- components of the stress tensor in the framework of the model of elastic deformations:

$$
\sigma_{\mathrm{ij}}=\lambda \mathrm{I}_{1}(\varepsilon) \mathrm{g}_{\mathrm{ij}}^{0}+2 \mu \varepsilon_{\mathrm{ij}}
$$

where $\lambda$ and $\mu$ - the Lame parameters of the material, and $I_{1}(\varepsilon)$ - the first invariant of the deformation tensor:

$$
I_{1}(\varepsilon)=\sum_{i, j=1}^{3} \varepsilon_{i j} g^{i j}
$$

where $\mathrm{g}^{\mathrm{i} j}$ - matrix components are inversed to $\mathrm{g}_{\mathrm{ij}}$

When reproducing the coordinates of points on the surface at the control time, interpolation (cubic spline, cubic spline with smoothing [11]) and least-squares approximation procedures are widely used [18]. These algorithms are implemented using standard software packages [19].

The values of mechanical stresses obtained according to the procedure (4)-(14) characterize the real stresses - in the case when it can be assumed that at the initial moment of time the stress in the vessel working under pressure is zero. If, at the initial time, the stresses are unknown, the obtained values will characterize the change in the stressed state of the vessel operating under pressure.

The obtained values of stresses (or characteristics of their changes) are obtained without using mathematically formalized values of forces, loads of different nature that act on the object. The found components can be written:

$$
\sigma_{\mathrm{ij}}=\sigma_{\mathrm{ij}}^{\mathrm{t}}+\sigma_{\mathrm{ij}}^{\mathrm{uf}}
$$

where $\sigma_{\mathrm{ij}}$ - stresses found by (14); $\sigma_{\mathrm{ij}}^{\mathrm{t}}$ - the value of the stresses that can be determined theoretically (ring stresses from the action of internal pressure, temperature differences, etc.). As a rule, the stresses are indicated at the same point at each point of the body or as functions of spatial coordinates; $\sigma_{\mathrm{ij}}^{\mathrm{uf}}$ - residual, unformalized stress, the nature of which often remains unknown. In particular, for a cylindrical part of a vessel, the stresses are determined from known formulas.

For a pipe subjected to an internal pressure $\mathrm{Pa}$ :

$$
\begin{gathered}
\sigma_{r r}=\frac{\mathrm{R}_{\mathrm{ID}}^{2} \cdot \mathrm{P}}{\mathrm{R}_{\mathrm{OD}}^{2}-\mathrm{R}_{\mathrm{ID}}^{2}} \cdot\left(1-\frac{\mathrm{R}_{\mathrm{OD}}^{2}}{\mathrm{r}^{2}}\right), \\
\sigma_{\theta \theta}=\frac{\mathrm{R}_{\mathrm{ID}}^{2} \cdot \mathrm{P}}{\mathrm{R}_{\mathrm{OD}}^{2}-\mathrm{R}_{\mathrm{ID}}^{2}} \cdot\left(1+\frac{\mathrm{R}_{\mathrm{OD}}^{2}}{\mathrm{r}^{2}}\right), \\
\sigma_{\mathrm{zz}}=\frac{\lambda}{\lambda+\mu} \cdot \frac{\mathrm{R}_{\mathrm{ID}}^{2} \cdot \mathrm{P}}{\mathrm{R}_{\mathrm{OD}}^{2}-\mathrm{R}_{\mathrm{ID}}^{2}} .
\end{gathered}
$$

For a spherical part, as shown in Fig. 5, where $\alpha$ - the angle defining the part of the sphere that is the upper dome of the vessel, $\varphi$ - the angle value for the given point; $\mathrm{H}$ - the wall thickness, $\mathrm{R}$ - the radius of curvature. All the components of the stress tensor are defined by the formulas:

Meridional stresses under the action of its own weight:

$$
\sigma_{\mathrm{m}}=-\frac{\gamma_{\mathrm{m}} \cdot \mathrm{R}}{1+\cos \varphi}
$$

where $\gamma_{\mathrm{m}}-$ density of material. 
Ring stresses:

$$
\sigma_{\theta \theta}=\gamma_{\mathrm{m}} \cdot \mathrm{R} \cdot \frac{1-\cos \varphi-\cos ^{2} \varphi}{1+\cos \varphi}
$$

Under the action of pressure $\mathrm{P}[12]$ :

$$
\sigma_{\mathrm{m}}=\sigma_{\theta \theta}=\frac{\mathrm{PR}}{2 \mathrm{~h}}
$$

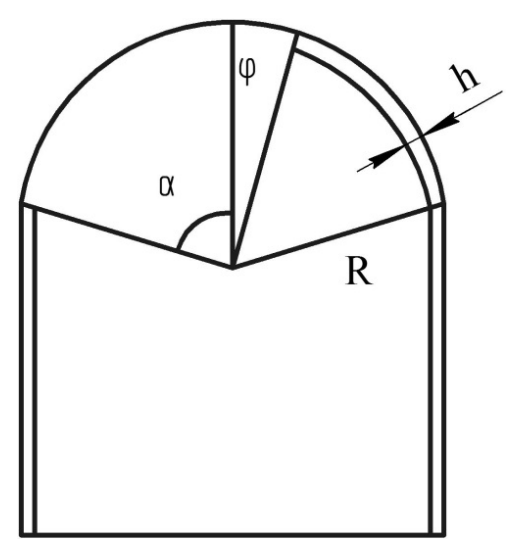

Fig. 5. Scheme of the spherical part

For the conical part, as shown in Fig. 6, under the influence of internal pressure, stresses arise (where $\mathrm{h}$ - the wall thickness, $\omega$ - the displacement in the direction of the normal, $2 \alpha-$ the angle at the conic vertex):

$$
\begin{aligned}
& \sigma_{\mathrm{m}}=\frac{\mathrm{pxtg} \alpha}{2 \mathrm{~h}} ; \\
& \sigma_{\theta \theta}=\frac{\mathrm{pxtg} \alpha}{\mathrm{h}} ; \\
& \omega=\frac{3 \mathrm{px}^{2} \operatorname{tg}^{2} \alpha}{4 \mathrm{hE}},
\end{aligned}
$$

where E- Young's modulus of material.

The above formulas concern only the basic, most easily formalized stresses.

The subject of further research is the stress $\sigma_{\mathrm{ij}}^{\mathrm{H}}$, calculation by (4)-(15) with allowance for (16)-(22). The nature of these stresses is unknown, therefore it is necessary to put forward a hypothesis on what parameters these stresses depend on, what is the reason for their occurrence. The stress can depend on the physical and mechanical properties of the material, electrical parameters, etc. Let $\mathrm{x}_{\mathrm{i}} \ldots \ldots \mathrm{x}_{\mathrm{N}}-\mathrm{N}-$ factors affecting on $\sigma_{\mathrm{ij}}^{\mathrm{H}}$. If measurements $\sigma_{\mathrm{ij}}^{\mathrm{H}}$, are made for different values of the parameters $\mathrm{x}_{\mathrm{i}}$, then to determine the degree of interrelation between $\sigma_{\mathrm{ij}}$ and $\mathrm{x}_{\mathrm{i}}$ the method of associative analysis is used. For $\sigma_{\mathrm{ij}}^{\mathrm{H}}$, and $\mathrm{x}_{\mathrm{i}}$, the values of $\sigma$ and $\mathrm{X}^{\mathrm{i}}$ are determined, which determine the median of the distribution of these quantities for their range changes, while the Table $\mathbf{1}$ is completed, which contains the results of $\mathrm{N}$ experiments by the criterion of their hit in the corresponding interval. This yields [19]. 


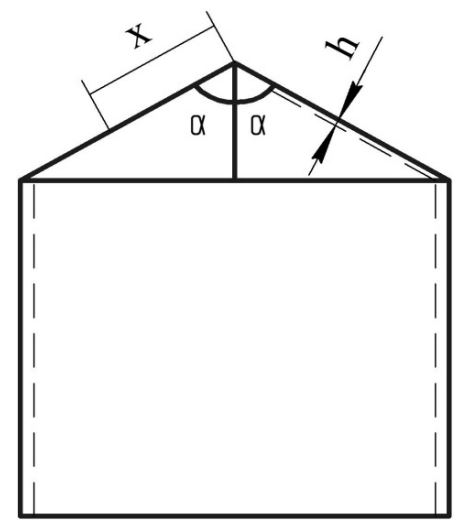

Fig. 6. Diagram of a conic vertex

Table 1

The results of $\mathrm{N}$ experiments on the criterion of their entry into the corresponding interval

\begin{tabular}{|c|c|c|c|c|}
\hline & $\sigma_{\mathrm{ij}}^{\mathrm{H}}>\boldsymbol{\sigma}$ & $\sigma_{\mathrm{ij}}^{\mathrm{H}}>\boldsymbol{\sigma}$ & & \\
\hline$x_{i}<X^{i}$ & $\mathrm{a}$ & $\mathrm{b}$ & $a+b$ & \\
\hline$x_{i}>X^{i}$ & $\mathrm{c}$ & d & $c+d$ & $\mathrm{a}+\mathrm{b}+\mathrm{c}+\mathrm{d}=\mathrm{N}$ \\
\hline & $\mathrm{a}+\mathrm{c}$ & $\mathrm{b}+\mathrm{d}$ & $\mathrm{N}$ & \\
\hline
\end{tabular}

where $a, b, c, d-$ the number of experiments with the corresponding values $\left(x_{i} ; \sigma_{i j}^{H}\right)$. Then the coefficients are determined:

$$
\begin{gathered}
\psi_{\mathrm{T}}=\frac{3}{\sqrt{\mathrm{N}-1}}, \\
\psi_{\mathrm{E}}=\frac{\mathrm{ad}-\mathrm{bc}}{\sqrt{(\mathrm{a}+\mathrm{b})(\mathrm{c}+\mathrm{d})(\mathrm{a}+\mathrm{c})(\mathrm{b}+\mathrm{d})}} .
\end{gathered}
$$

If $\Psi_{\mathrm{E}}>\Psi_{\mathrm{T}}$, then the relationship between $\mathrm{x}_{\mathrm{i}}$ and $\sigma_{\mathrm{ij}}^{\mathrm{H}}$ is significant, it requires further investigation; if $\Psi_{\mathrm{E}}<\Psi_{\mathrm{T}}$, then the relationship between the quantities is not significant, it can be neglected. With a significant relationship between the values $\sigma_{\mathrm{ij}}^{\mathrm{H}}$ and $\mathrm{x}_{\mathrm{i}}, \mathrm{k}=1,2,3$ the least square method can be used to construct an incomplete cubic model of the form:

$$
\begin{aligned}
\sigma_{\mathrm{ij}}^{\mathrm{H}}=\eta\left(\mathrm{x}_{1} \mathrm{x}_{2} \mathrm{x}_{2}\right)= & \theta_{0}+\theta_{1} \mathrm{x}_{1}+\theta_{2} \mathrm{x}_{2}+\theta_{3} \mathrm{x}_{3}+\theta_{12} \mathrm{x}_{1} \mathrm{x}_{2}+\theta_{13} \mathrm{x}_{1} \mathrm{x}_{3}+ \\
& +\theta_{23} \mathrm{x}_{2} \mathrm{x}_{3}+\theta_{123} \mathrm{x}_{1} \mathrm{x}_{2} \mathrm{x}_{3},
\end{aligned}
$$

which under certain conditions [19] can be adequately replaced by a linear model:

$$
\sigma_{\mathrm{ij}}^{\mathrm{H}}=\eta\left(\mathrm{x}_{1} \mathrm{x}_{2} \mathrm{x}_{2}\right)=\theta_{0}+\theta_{1} \mathrm{x}_{1}+\theta_{2} \mathrm{x}_{2}+\theta_{3} \mathrm{x}_{3}
$$

The choice of representation (25) or (26) makes it possible to obtain relationships convenient for practical analysis between stresses and identified factors of influence on SSS, and also to analyze these dependencies to assess the relative influence of each of the identified factors. 


\section{Research results of the stress-strain state of vessels working under pressure and factors of force influence}

In the process of researching ways to determine the actual technical condition of high-risk facilities, namely vessels operating under the pressure, through SSS determination, the following results are achieved:

1. The type of the mathematical model is established. An algorithm for regularizing the incorrect problem of SSS recovery from incomplete information on the displacement of the surface points is proposed.

2. A methodology for calculating the components of strain tensors has been developed, namely, a technique for determining the SSS of objects using a metric tensor for undeformed and deformed vessels is proposed.

3. Identification of the force factors. It is proposed to use the method of associative analysis to identify significant factors of influence.

Also, an important achievement is the determination of the direction of further research, namely the experimental work on the models of pressure vessels, in order to obtain a set of informative parameters. Industrial testing is carried out.

\section{Discussion of research results of the stress-strain state of vessels and the choice of factors of force action}

The advantages of the proposed method for SSS evaluation of vessels operating under pressure include the moment that information about deformation is obtained without using data on all forces and loads that last for a long time on the object. In fact, this information is some integral characteristic of the object.

The proposed technique for determining and evaluating the stress state is carried out by means of multivariable control. It allows to take into account several additional factors of influence that have not been taken into account and on which the behavior of the change in the stress state depends. The technique of multivariable control is convenient for use in the field conditions. The main disadvantage is the multiple measurements of a set of informative parameters and the use of several means of measurement.

The conducted studies use the approaches and mathematical models developed for SSS research of the main pipelines. These models are improved taking into account the more complex spatial configuration of the object. For the first time, a technique is proposed for identifying the factors of force action, which cause the appearance of asymmetric deformations of the object.

\section{Conclusions}

1. The mathematical formulation of the problem of SSS evaluation on the basis of experimental data is formulated as an incorrect problem of reconstructing the displacement field for vessels with different types of domes from data on the displacement of a certain set of points of the object.

2. A mathematical model of the vessel's SSS has been developed, as an algorithm for regularizing an ill-posed problem.

3. The relationship between real SSS and standard loads for structures with different types of domes is established in order to identify zones of asymmetric stresses.

4. The technique of determining the factors of force actions is proposed, most of all they affect the SSS of designs using the methods of associative analysis.

5. Advantages of this method is a comprehensive assessment of the actual technical condition for many informative parameters, depend on the force factors of influence, and the evaluation of SSS parameters is made without using information about the forces and loads acting on the object.

6 . The disadvantages include the process of multiple measurements of informative parameters using a large number of technical means of control. Also, to obtain the results of the SSS level, further processing of the measurement results is necessary.

7. To consolidate the proposed technique, it is necessary to conduct experimental studies on model samples of pressure vessels and to conduct industrial approbation. It is suggested to use the above approaches for evaluation of SSS parameters for objects where only measuring the movement of points on the surface is possible without carrying out more complicated hardware studies. 


\section{References}

[1] Kliuev, V., Fursov, A., Fylynov, M. (2007). Podkhody k postroeniyu system otsenki ostatochnoho resursa tekhnicheskikh obektov. Kontrol. Diahnostika, 3, 18-23.

[2] Karpash, A., Tatsakovych, N., Dotsenko, Ye. (2016). Features of the modern control techniques application to determine metal constructions deflected mode. Scientific proceedings «NDT Day 2016», 1 (187), 319-324.

[3] Karpash, O., Karpash, M., Dotsenko, Ye. (2008). Doslidzhennia vzaiemozviazku mizh strukturnym stanom stalei ta fizyko-mekhanichnymy kharakterystykamy stalei. Fizyko-khimichna mekhanika materialiv, 2 (7), 724-729.

[4] Karpash, A. (2012). Analiz vidomykh metodiv kontroliu fizyko-mekhanichnykh kharakterystyk metalu. Naftohazova enerhetyka, 1 (17), 70-82.

[5] Vashchyshak, S., Karpash, A. (2012). Current approaches to the determination of physic-mechanical properties of metals oil and gas facilities. Scientific proceedings «NDT Day 2012», 1 (133), 260-264.

[6] Skalsky, V., Hirnyj, S., Basarab, R. (2013). Nondestructive evaluation of pipelines: magnetoacoustic diagnostics of deformation. Oil and Gas Business, 5, 301-313.

[7] Karpash, M., Dotsenko, Ye., Tatsakovych, N. (2011). New non-destructive methods for physical and mechanical properties evaluation of metalworks materials. Edition of Scientific Machine Union, 19, 32-36.

[8] Piotrowski, L., Augustyniak, B., Chmielewski, M., Kowalewski, Z. (2010). Multiparameter analysis of the Barkhausen noise signal and its application for the assessment of plastic deformation level in 13HMF grade steel. Measurement Science and Technology, 21 (11), 115702. doi: 10.1088/09570233/21/11/115702

[9] Wang, Z. D., Gu, Y., Wang, Y. S. (2012). A review of three magnetic NDT technologies. Journal of Magnetism and Magnetic Materials, 324 (4), 382-388. doi: 10.1016/j.jmmm.2011.08.048

[10] Bogusz, P., Poplawski, A., Morka, A., Niezgoda, T. (2015). Evaluation of true stress in engineering materials using optical deformation measurement methods. Journal of KONES. Powertrain and Transport, 19 (4), 53-64. doi: 10.5604/12314005.1138307

[11] Oliinyk, A. (2010). Matematychni modeli protsesu kvazistatsionarnoho deformuvannia truboprovidnykh ta promyslovykh system pry zmini yikh prostorovoi konfihuratsii. Ivano-Frankivsk: IFNTUNH, 320.

[12] Pisarenko, G., Yakovlev, A., Matveev, V. (1988). Spravochnyk po soprotyvlenyiu materyalov. Kyiv: Naukova dumka, 736.

[13] Pravyla bezpeky i bezpechnoi ekspluatatsii posudyn, shcho pratsiuiut pid tyskom: NPAOP 0.001.59-87 (1987). Derzhhirpromnahliad.

[14] Posudyny, shcho pratsiuiut pid tyskom na promyslovykh pidpryiemstvakh: Instruktsiia z ekspertnoho obstezhennia (Tekhnichnoho diahnostuvannia) (2006). Ministerstvo promyslovoi polityky Ukrainy.

[15] Obladnannia tekhnolohichne naftopererobnykh, naftokhimichnykh ta khimichnykh vyrobnytstv. Tekhnichne diahnostuvannia. Zahalni tekhnichni vymohy: DSTU 4046-2001 (2001). Derzhstandart Ukrainy.

[16] Sosudi y apparati. Normi y metodi rascheta na prochnost: HOST-14249-89 (1989). Mynysterstvo khymycheskoho y neftianoho mashynostroenyia.

[17] Sedov, L. (1970). Mekhanyka sploshnikh sred. Vol. 2. Moscow: Nauka, 572.

[18] Samarskyi, A., Hulyn, A. (1989). Chyslennie metody. Moscow: Nauka, 432.

[19] Doroshenko, V. (1993). Osnovy naukovykh doslidzhen. Kyiv: ISDO, 128. 